\title{
REVIEW
}

\section{RNAs as extracellular signaling molecules}

\author{
Marcel E Dinger*, Timothy R Mercer* and John S Mattick \\ Institute for Molecular Bioscience, ARC Special Research Centre for Functional and Applied Genomics, University of Queensland, Brisbane QLD 4072, Australia
}

(Correspondence should be addressed to J S Mattick; Email: j.mattick@imb.uq.edu.au)

*(M E Dinger and T R Mercer contributed equally to this work)

\begin{abstract}
RNA is emerging as a major component of the regulatory circuitry that underpins the development and physiology of complex organisms. Here we review recent evidence that suggests that RNA may supplement endocrine and paracrine signaling by small molecules and proteins, and act as an efficient and evolutionarily flexible source of sequence-specific information transfer between cells, both locally and systemically. As such, RNA signaling may play a central but previously hidden role in multicellular ontogeny, homeostasis, and transmitted epigenetic memory.
\end{abstract}

Journal of Molecular Endocrinology (2008) 40, 151-159

\section{Introduction}

The emergence of non-protein-coding RNA (ncRNA) as an important regulatory molecule within the cell (Mattick \& Makunin 2006, Prasanth \& Spector 2007) forces a reconsideration of the role of RNA in a number of cellular processes previously considered to be the predominant or exclusive domain of proteins. This includes the potential of RNA to mediate cell-to-cell communication. The ability of RNA to compactly store and transmit information makes it an ideal medium to communicate between and co-ordinate the functions of cells in multicellular organisms. Indeed, the ability of RNA to propagate information between the cells and even between the organisms has been illustrated to devastating effect by the existence of retroviruses such as HIV.

Although only $1.2 \%$ of the mammalian genome encodes protein, a significant fraction is under evolutionary selection (Pheasant \& Mattick 2007) and most is transcribed in complex interleaved patterns of protein-coding and non-coding RNAs (ncRNAs; Mattick \& Makunin 2006, Birney et al. 2007, Kapranov et al. 2007a). The latter comprise a diverse range of classes (summarized in Table 1) that include small regulatory RNAs, such as microRNAs (miRNAs), small interfering RNAs (siRNAs), and small nucleolar RNAs, as well as long ncRNAs that can be sourced from genomic regions that are intergenic, intronic, antisense, or overlapping with protein-coding genes. In mammals, tens of thousands of long ncRNAs have been identified, many of which exhibit distinct expression profiles in different cells and tissues (Ravasi et al. 2006, Mercer et al. 2008). There is also evidence for very large number of small RNAs (Berezikov et al. 2006, Mineno et al. 2006, Kapranov et al. 2007b). Although the role of a limited number of ncRNAs has been determined (Mattick \& Makunin 2006, Prasanth \& Spector 2007), the function of the vast majority is unknown.

The physicochemical properties of RNA enable it to fulfill a diverse range of structural and catalytic roles through various mechanisms (Scott 2007). These characteristics are fundamental to key cellular processes, such as translation and splicing, and are also central to the hypothesis that RNA formed the initial molecular basis for life on Earth (Joyce 2002, Orgel 2004). In addition to the ribosomal and spliceosomal RNAs, the ncRNAs have been shown to be involved in a diverse range of biological pathways and processes (Mattick \& Makunin 2006), including cellular differentiation and development (Martinho et al. 2004, Wienholds et al. 2005, Zhao et al. 2005), chromatin modification (Bernstein \& Allis 2005, Rinn et al. 2007), imprinting (Hatada et al. 2001, Sleutels et al. 2002, Okamoto et al. 2005), alternative splicing (Kishore \& Stamm 2006), nuclear factor trafficking (Willingham et al. 2005), RNA modification (Kiss 2002), and mRNA translation and stability (Bartel 2004).

Recent years have seen that RNA move into mainstream thinking in biology as a key player in information transfer and regulatory control (Mattick 2007). This is beyond the established role of RNA as an intermediate between gene and protein or as an infrastructural 
Table 1 Summary of major classes of non-coding RNAs with regulatory roles

\section{Description}

ncRNA

miRNA

siRNA

snoRNA

long ncRNAs

piRNAs

Riboswitches
MicroRNAs (miRNAs) are small ( $\sim 21-23 \mathrm{nt}$ ) single-stranded RNAs that regulate gene expression by partial complementary base pairing to specific mRNAs. This annealing inhibits protein translation and in some cases facilitates degradation of the mRNA

Small interfering or silencing RNAs (siRNAs) are small ( $\sim 20-25 \mathrm{nt})$ double-stranded RNAs that act through the RNA interference (RNAi) pathway to interfere with the expression of a specific gene containing a complementary sequence. RNAi can down-regulate expression by inducing degradation of the targeted RNA, interfering with transcription or inducing epigenetic changes to the gene

Small nucleolar RNAs (snoRNAs) are small ( 70-240 nt) RNAs that guide the methylation or pseudouridylation of rRNAs and other RNAs. SnoRNAs contain a 10-20 nt antisense sequence that is complementary to the sequence adjacent to the base targeted for modification

Long ncRNAs are generally defined as RNAs longer than $200 \mathrm{nt}$ with little or no protein-coding capacity. Long ncRNAs can regulate gene expression through diverse mechanisms

Piwi-interacting RNA (piRNA) are small (27-30 nt) RNAs that are specifically expressed in the Drosophila and vertebrate germ line. piRNAs interact with Piwi proteins to direct chromatin modifications and transposon silencing

A riboswitch is a part of an RNA that binds a small molecule ligand, such as an amino acid or co-factor, to cause a structural change that alters the function or expression of the RNA, such as modification of pre-mRNA splicing or mRNA translation. Most known riboswitches occur in bacteria, but they have also been discovered in eukaryotes component in splicing and translation. Indeed, the widespread developmentally regulated expression of ncRNAs, both intronic and intergenic, has led to the proposal that these RNAs form a hidden layer of regulation that controls various cellular processes, in particular developmental trajectories (Mattick 1994, 2003, 2004, 2007) and brain function (Mehler \& Mattick 2007, Mercer et al. 2008). Here we discuss the emerging evidence that one aspect of such a non-coding regulatory network may be its ability to mediate extracellular communication in multicellular organisms.

\section{RNA as a signaling molecule}

RNA has several advantages as a signaling molecule. First, it can encode sequence-specific interactions using base-pairing rules and specificities. Such sequencespecific interactions may be likened to digital signals and can occur over short stretches of nucleotides (e.g., $\sim 22 \mathrm{nt}$ miRNAs and siRNAs that regulate mRNA translation and turnover) in a more precise and efficient manner than can be achieved by proteins, which require complex tertiary structures to targetspecific nucleotide sequences. Secondly, RNAs can act as molecular adaptors to connect incoming analog signals to sequence-specific outcomes. This is exemplified by 'riboswitches' which are mRNA elements that alter their structure in response to ligands, enabling them to sense and react to environmental parameters (Winkler \& Breaker 2005, St Laurent \& Wahlestedt 2007). RNAs can also function as adaptors to connect the complexes formed by RNA:RNA and RNA:DNA interactions to a generic protein infrastructure that can act upon these signals in a way that is determined by the characteristics of the regulatory RNA or the resulting complex (Mattick 2007). This capacity enables the flexibility to create new members of various classes of RNA signaling molecules that vary in their target specificity, but utilize a common infrastructure and output pathways, thereby providing latitude to explore new connections in RNA-based regulatory networks (Mattick \& Gagen 2001, Mattick 2007). Well-characterized examples include the recruitment of the RNAinduced silencing complex to mRNA:miRNA/siRNA complexes (Bartel 2004, Sontheimer 2005) and the evolution of lineage-specific miRNAs (Berezikov et al. 2006), as well as the snoRNA-mediated recruitment of generic enzyme complexes to impose site-specific base modifications on target RNAs (Bachellerie et al. 2002). Similarly, the promoter-directed RNAs that have been shown to regulate gene expression (Han et al. 2007, Martianov et al. 2007) presumably interact with relatively generic transcription factors and/or direct chromatin-modifying complexes to induce epigenetic changes at loci targeted via sequence-specific interactions (Mattick 2007), in one case involving RNA:DNA triplex formation (Martianov et al. 2007). Triplexes (Ohno et al. 2002) and promoter-associated RNAs (Kapranov et al. 2007b) occur genome wide and it seems plausible that many genes may be regulated by such signals and associated general mechanisms.

This intracellular signaling paradigm may be extended to include extracellular signaling whereby a 
generic infrastructure is employed to transport and receive specific RNA signals in the extracellular milieu, independently of their information content, analogous to a postal system whereby an RNA 'cargo' is delivered by the protein 'courier'. Such systems would also involve generic infrastructural components such as cell surface receptors and transport vesicles (see below) that may transmit different RNA molecules regardless of their precise sequence. As such, RNA could transmit a range of signals to other cells without having to evolve novel signal-specific pathways, a further advantage of RNA in the context of lineage-specific developmental and physiological regulation.

\section{RNA as an extracellular signal}

Clear evidence that RNA can act as an extracellular signal is emerging. Studies in plants first showed that the phenomenon of co-suppression in response to transgene expression is mediated by RNA signaling (Napoli et al. 1990, van der Krol et al. 1990, Smith et al. 1994), and that this effect, which involves the RNA interference (RNAi) pathway, can be transmitted plant wide following grafting of an affected rootstock onto a scion (Palauqui et al. 1997, Voinnet \& Baulcombe 1997, Garcia-Perez et al. 2004). The graft-transmissible signal, presumed to be RNA, is delivered into the nucleus where it causes transcriptional down-regulation of homologous chromatin, as well as degradation of homologous transcripts (Brosnan et al. 2007). Plants use the same or closely related pathways to help co-ordinate developmental processes (Vaucheret \& Fagard 2001), and translocated RNA has been demonstrated to affect leaf development (Kim et al. 2001). The transport of these RNA signals occurs in local proximity via plasmodesmata or systemically via phloem (Himber et al. 2003).

The molecular nature of the graft-transmissible regulatory RNA signal in plants is yet to be determined but recent results indicate that it may not be simply miRNA or siRNA (Brosnan et al. 2007). In plants, there are four DICER-like (DCL) proteins that process double-stranded RNA (dsRNA) into miRNA and siRNA. DCL1 produces miRNAs, whereas siRNAs that are responsible for the silencing of viruses, transposons, and transgenes are produced by the combined action of DCL2, DCL3, and DCL4 (Bouche et al. 2006, Deleris et al. 2006, Fusaro et al. 2006). A dcl1 mutant and a $d c l 2-d c l 3-d c l 4$ triple mutant that are compromised in miRNA and siRNA biogenesis, respectively, are not affected in transmission of the mobile silencing signal from the rootstock into the scion (Brosnan et al. 2007). These results indicate that the graft-transmissible regulatory RNA signals in plants may be another form of RNA (Brosnan et al. 2007).
There is also evidence for systemic RNA signaling in animals. The discovery of RNAi in the nematode Caenorhabditis elegans showed that RNA signals can be transmitted both from the environment (via ingestion) and systemically throughout the organism (Fire et al. 1998). Injection of exogenous dsRNA into a few cells was followed by whole organism knockdown of the homologous target mRNA sequences, an effect that can be inherited for several generations (Tavernarakis et al. 2000). This process involves a set of proteins, including cell surface receptors, at least some of which are conserved in most animals, including mammals (Jose \& Hunter 2007; see below). Extracellular RNA is also present and circulates in the vascular system of mammals (Tsang \& Lo 2007) and fetal mRNA has even been found within the blood of pregnant women (Lo 2005). Although the circumstantial evidence is strong, there is as yet no direct evidence that systemic RNA signaling occurs in mammals, nor that extracellular RNA signaling networks participate in normal physiological processes.

\section{Transport of RNA across cell membranes}

The phospholipid membrane of eukaryotic cells presents a strong barrier to the passive diffusion of nucleic acids. Consequently, it would be expected that cells would require pathways for the import of RNA from other cells and the extracellular milieu. Interestingly, while cells are relatively impermeable to exogenous mononucleotides, oligonucleotides can easily be taken up by cells, where they can modulate internal cellular processes such as splicing (Kole \& Sazani 2001). Although mechanisms of RNA uptake by mammalian cells are not well understood, the RNAs are known to enter cultivated mammalian cells by natural processes, including direct cell-to-cell contact, membrane receptors, and channels (Feinberg \& Hunter 2003, Valiunas et al. 2005).

In cases where cells are in close proximity they may connect physically to allow direct communication and RNA transfer. For example, mRNA required for Drosophila oocyte specification and growth is transcribed in neighboring nurse cells and trafficked through connecting ring canals to the oocyte in the egg chamber (Steinhauer \& Kalderon 2006). Similarly, RNA within chromatid bodies is transferred between germ cells via cytoplasmic bridges during mouse spermatogenesis (Ventela et al. 2003), and there is evidence to suggest that axoplasmic and pre-synaptic RNAs in neurons derive from nearby glial cells (Eyman et al. 2007). Long membranous tubes, known as tunneling nanotubes, were recently discovered connecting a number of somatic cells (Rustom et al. 2004). While the physiology and extent to which these tubes 
occur between cells is unknown, they have been shown to permit the exchange of cytoplasmic contents between the cells. Gap junctions, small channels that allow small molecules to be transferred directly between the cytoplasm of neighboring cells, were recently shown to permit movement of siRNAs between adjacent human embryonic stem (ES) cells with resultant effects on gene expression (Wolvetang et al. 2007).

Genetic screens have identified a number of genes required for the spread of systemic RNAi in C. elegans. The best characterized to date, Sid-1, encodes a transmembrane protein that allows the import of dsRNA into the cell (Winston et al. 2002, Feinberg \& Hunter 2003). Another gene, Sid-2, encodes an intestinal luminal transmembrane protein required for environmental RNAi, but interestingly this protein is not present in all nematodes (Winston et al. 2007). Orthologs of Sid-1 are present in most animals (Li et al. 2006). Mammals contain two paralogs of Sid-1 (Sidt1 and Sidt2), which suggests that mammals have evolved additional specialized RNA transport functions. The human Sid-1 ortholog, SIDT1, has been confirmed to import dsRNA similarly across the cell membrane (Duxbury et al. 2005, Wolfrum et al. 2007), and microarray analyses indicate that both Sid-1 paralogs are expressed in most tissues and cell types in humans and mice (Su et al. 2004). In mice, Sidt1 and Sidt2 exhibit specific expression patterns in the brain, suggesting that dsRNAs are transported intercellularly in the brain (Fig. 1) and that these two proteins fulfill distinct functions. Further, given the impermeability of the blood-brain barrier to even small RNAs, it may be that this barrier functions in part to segregate such an intercellular RNA signaling network from systemic circulation.

\section{RNA signaling in the germ line}

One exciting finding to emerge from genetic screens of C. elegans was the discovery of three genes, $r s d-2, r s d-3$, and $r s d-6$, required for the transfer of dsRNA into germ line cells (Tijsterman et al. 2004). Although little is known about the function of these genes, the protein encoded by $r s d-3$, which has both mouse and human orthologs, contains an ENTH (epsin NH2-terminal homology) domain that is commonly found in proteins involved in vesicle trafficking. However, $r s d$ mutants do not exhibit generalized defects in endocytosis, suggesting the existence of a specific pathway for the import of silencing signals into the germ line (Tijsterman et al. 2004), and providing a means by which environmental factors may lead to heritable changes. Indeed, RNAi-mediated silencing can be inherited for several generations in C. elegans (Vastenhouw et al. 2006) and, since this process involves a number of chromatin remodeling factors, it is likely that the intergenerational transmission of the signal requires epigenetic modifications.

There is abundant evidence that ncRNAs regulate chromatin architecture (Bernstein \& Allis 2005, Mattick 2007, Rinn et al. 2007). The extracellular trafficking of such ncRNAs may impart heritable epigenetic modifications on the recipient cell, and these extracellular signals may themselves be potentially inherited through generations in both plants and animals. The existence of such pathways is supported by the recently discovered phenomenon of paramutation that involves the epigenetic transfer of information from one allele of a gene to another and is thought to be primarily mediated by trans-acting RNAs (Alleman et al. 2006, Rassoulzadegan et al. 2006, Chandler 2007). This process can be directed by miRNAs as well as other small RNAs and appears to require the action of the RNA methyltransferase Dnmt2 (Cuzin 2007). Similar to the blood-brain barrier, the blood-testis barrier (Russell 1977) may also have a role in privileging organ-specific RNA signaling or quarantining the male reproductive organ from non-specific systemic RNA signaling. It may also provide a checkpoint to regulate the transfer of specific RNA signals into the testes, which may be crucial if extracellular RNA signals are indeed able to induce heritable effects.

\section{Vesicle-mediated RNA transport}

RNA is labile in the mammalian circulatory system, as illustrated by the rapid degradation of exogenous RNA in plasma or blood (Tsui et al. 2002, 2006). However, some forms of circulating endogenous RNA seem to be stable and protected from degradation during systemic transport (Tsui et al. 2002). Endogenous RNA is unable to pass through size-exclusion filters permeable to free RNA or DNA, and the addition of detergents results in the immediate degradation of endogenous RNA ( $\mathrm{Ng}$ et al. 2002, Tsui et al. 2002). This suggests that RNA is associated with, and protected by, lipid and/or protein in the systemic circulation.

Microvesicles are spherical fragments of plasma membrane that are emitted from a wide range of cells (Thery et al. 2002, Fevrier \& Raposo 2004). They may originate directly from the cell surface and co-opt host membrane components and engulfed cytoplasmic contents during their formation, or they may also be secreted from the endosomal compartment. Microvesicles are known to play important roles in a number of biological processes, including oncogenesis (Ratajczak et al. 2006a), coagulation (Barry \& FitzGerald 1999), immune responses (Barry \& FitzGerald 1999), and modulation of susceptibility/infectability 

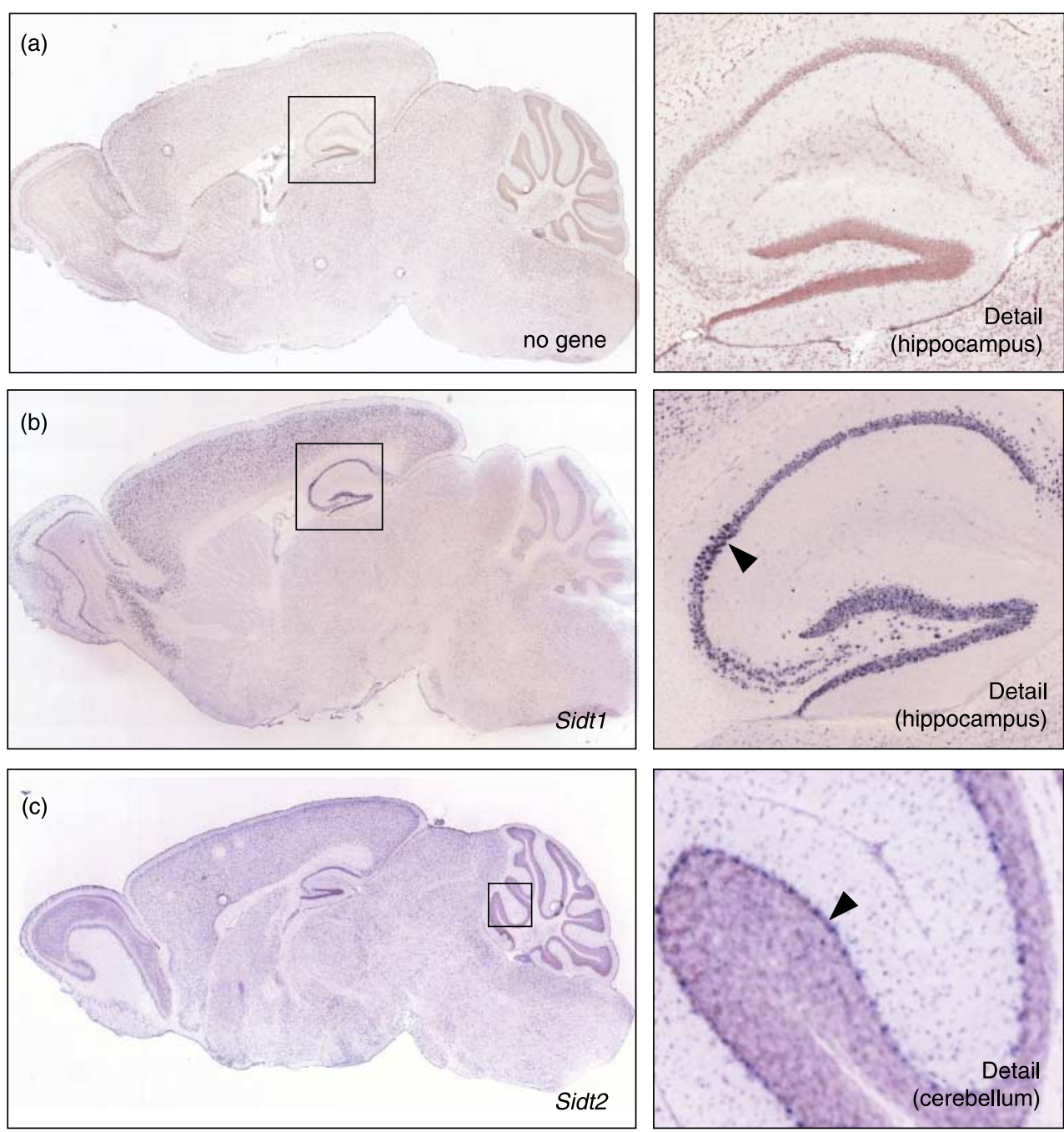

Figure 1 Sidt1 and Sidt2 expression in the adult mouse brain. (a) No probe control of adult mouse brain in sagittal section (with detail of hippocampus). (b) In situ hybridization of Sidt1 showing expression in the cerebral cortex, mitral layer of the olfactory bulb, and hippocampus. Close-up image (right) shows heterogenous expression of Sidt1 in the hippocampus. (c) In situ hybridization of Sidt2 showing expression broadly throughout the brain. Close-up image (right) shows specific expression of Sidt2 in the Purkinje cell layer of the cerebellum. Images courtesy of the Allen Brain Atlas (Lein et al. 2007).

of cells to retroviruses (Wiley \& Gummuluru 2006) or prions (Fevrier et al. 2005).

Evidence is emerging that microvesicles may contain RNA and are involved in cell-to-cell communication (Baj-Krzyworzeka et al. 2006, Ratajczak et al. 2006a). A recent study investigating interactions between tumorcell derived microvesicles and human monocytes found that mRNAs are contained within microvesicles of that then adhere to and are engulfed by monocytes (Baj-Krzyworzeka et al. 2007). Similarly, microvesicles obtained from mouse ES cells were shown to contribute to an up-regulation of pluripotency markers within recipient hematopoietic stem/progenitor cells and subsequently enhance their survival and expansion.
The ES cell-derived microvesicles were enriched for mRNAs encoding several pluripotent transcription factors, suggesting that RNA exchange occurs between stem cells, and presumably other cell types, during development (Ratajczak et al. 2006b).

A recent study examined the RNA content of 'exosomes' (small microvesicles that are processed and released from late endosomal compartments of many different cells) released by mast cells and identified functional mRNAs corresponding to $\sim 1300$ genes, many of which were not present within the donor cell (Valadi et al. 2007). It was also demonstrated that mouse exosomal mRNAs were translated in recipient human mast cells. Over 120 miRNAs were 
also identified within the mast cell-derived exosomes (Valadi et al. 2007). Some of the RNAs were expressed at higher levels or uniquely within the exosomes relative to the donor cell. This suggests the existence of dedicated cellular control mechanisms to collect and package specific RNAs into the exosome. Furthermore, our own analysis of the microarray results from this study revealed that many longer ncRNAs were also present in exosomes, including a number of ncRNAs associated with important genes and several known ncRNAs, such as Copg2as and Nespas (Supplementary Table 1 , which can be viewed online at http://jme. endocrinology-journals.org/content/vol40/issue3/).

\section{The response of the immune system to RNA}

In vertebrate cells, the introduction of RNA elicits an innate-immune response known as the interferon response, which leads to a prevention of mRNA translation and increased RNA degradation (Karpala et al. 2005). The potency of this interferon response is variable and seems to be cell-type specific (Reynolds et al. 2006). For example, neurons (Gan et al. 2002) and undifferentiated cells, such as oocytes (Stein et al. 2005) and ES cells (Yang et al. 2001), do not mount an interferon response upon the introduction of long dsRNAs. Furthermore, the introduction of mammalian RNA into human dendritic cells does not activate the interferon response (Kariko et al. 2005), suggesting that the innate immune response is able to distinguish between endogenous host RNA and exogenous (e.g., viral) RNA and is therefore unlikely to prevent the import of systemic RNA signals. It is thought that posttranscriptional RNA modifications (such as editing, methylation, $5^{\prime}$ capping, and polyadenylation) as well as compartmentalization of the innate immune response within the cell prevent this self-recognition (Ishii \& Akira 2005, Sioud 2006). This would help explain why synthetic unmodified RNA is immuno-stimulatory, but natural host RNA is not.

The efficient transmission of retroviruses, such as HIV, between cells and organisms illustrates the efficacy of RNA to transfer information. Indeed, some retroviruses may exploit natural mechanisms of RNA extracellular signaling to spread throughout the host organism. This notion is supported by a recent study showing that HIV may hijack exosomes emitted from dendritic cells (Wiley \& Gummuluru 2006) and thereby potentially allow it to evade immune recognition.

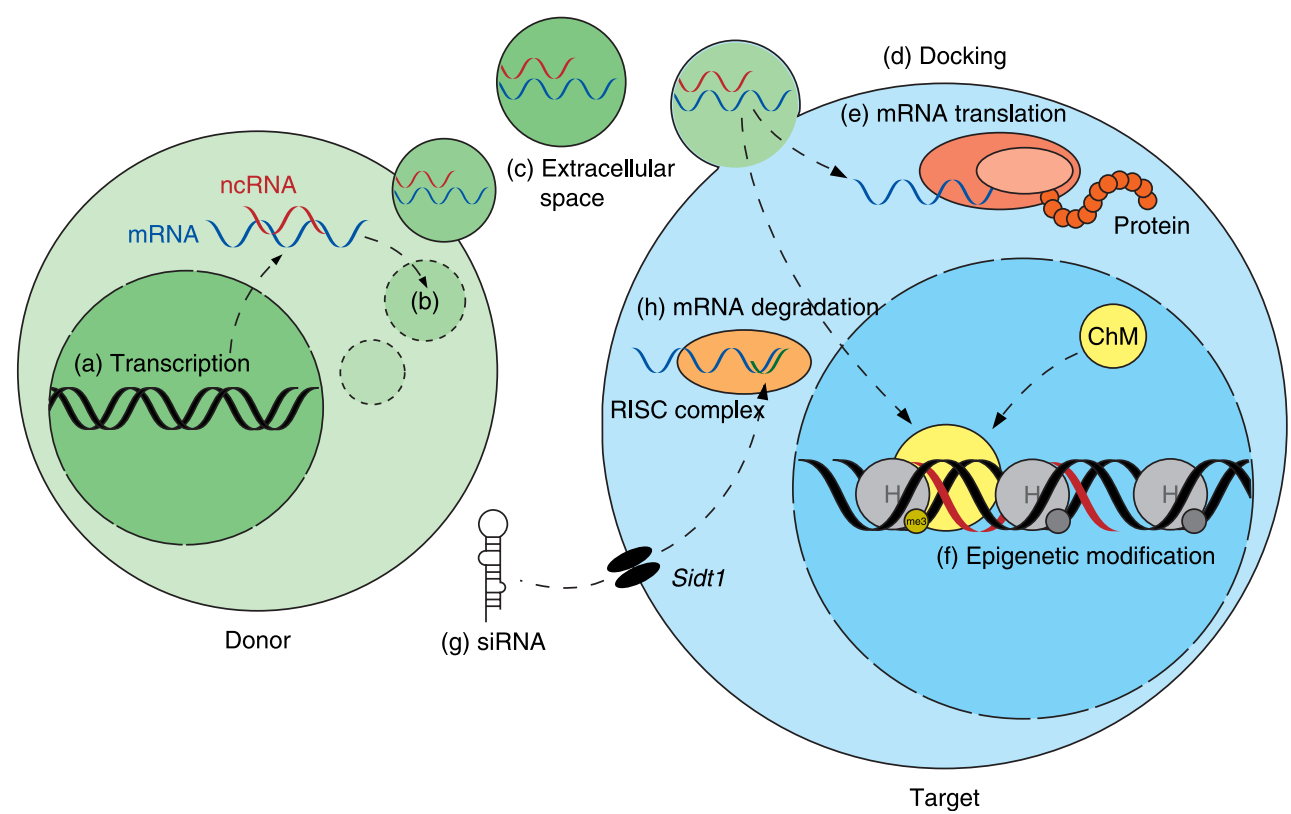

Figure 2 Schematic showing known and putative extracellular signaling pathways mRNA (blue) and ncRNA (red) are (a) transcribed in the donor cell. These RNAs are then (b) trafficked and packaged into vesicles, which are emitted into (c) the extracellular environment. (d) The vesicles then dock and fuse with the target cell, releasing their RNA content. The mRNA may then be (e) translated in the donor cell and the ncRNA may impart regulatory functions, such as guiding the catalytic function of chromatin modifying proteins $(\mathrm{ChM})$ to mediate $(\mathrm{f})$ epigenetic modifications. In addition (g) extracellular RNA signals, such as siRNAs or miRNAs, may be transferred across the plasma membrane by specific receptors and channels, such as Sid-1. (h) These signals may fulfill regulatory functions in the cell such as translation inhibition or mRNA degradation. 


\section{Conclusion}

While perhaps not surprising in retrospect, there is increasing experimental evidence to suggest that RNA has been widely adopted as a regulatory molecule not just within cells, but also systemically, as summarized in Fig. 2 . The harnessing of the power of RNA to transmit information between the cells, and between the generations, adds an exciting and previously hidden dimension to the intercellular communication systems that operate in development and physiology, whose details are still hazy and whose enormous implications have yet to be explored.

\section{Acknowledgements}

We thank our laboratory colleagues for stimulating discussions and their continuing enthusiasm. We thank Bernie Carroll (University of Queensland, Brisbane) and Mark Mehler (Albert Einstein College of Medicine, New York) for helpful comments on the manuscript. M E D is funded by a Foundation for Research, Science and Technology, New Zealand Fellowship. T R M is supported by an Australian Postgraduate Award. J S M is supported by an Australian Research Council Federation Fellowship, the University of Queensland and the Queensland State Government. The authors declare that there is no conflict of interest that would prejudice the impartiality of this scientific work.

\section{References}

Alleman M, Sidorenko L, McGinnis K, Seshadri V, Dorweiler JE, White J, Sikkink K \& Chandler VL 2006 An RNA-dependent RNA polymerase is required for paramutation in maize. Nature $\mathbf{4 4 2}$ 295-298.

Bachellerie JP, Cavaille J \& Huttenhofer A 2002 The expanding snoRNA world. Biochimie 84 775-790.

Baj-Krzyworzeka M, Szatanek R, Weglarczyk K, Baran J, Urbanowicz B, Branski P, Ratajczak MZ \& Zembala M 2006 Tumour-derived microvesicles carry several surface determinants and mRNA of tumour cells and transfer some of these determinants to monocytes. Cancer Immunology and Immunotherapy $\mathbf{5 5}$ 808-818.

Baj-Krzyworzeka M, Szatanek R, Weglarczyk K, Baran J \& Zembala M 2007 Tumour-derived microvesicles modulate biological activity of human monocytes. Immunology Letters 113 76-82.

Barry OP \& FitzGerald GA 1999 Mechanisms of cellular activation by platelet microparticles. Thrombosis and Haemostasis 82 794-800.

Bartel DP 2004 MicroRNAs: genomics, biogenesis, mechanism, and function. Cell 116 281-297.

Berezikov E, van Tetering G, Verheul M, van de Belt J, van Laake L, Vos J, Verloop R, van de Wetering M, Guryev V, Takada S et al. 2006 Many novel mammalian microRNA candidates identified by extensive cloning and RAKE analysis. Genome Research 16 1289-1298.

Bernstein E \& Allis CD 2005 RNA meets chromatin. Genes and Development 19 1635-1655

Birney E, Stamatoyannopoulos JA, Dutta A, Guigo R, Gingeras TR, Margulies EH, Weng Z, Snyder M, Dermitzakis ET, Thurman RE et al. 2007 Identification and analysis of functional elements in 1\% of the human genome by the ENCODE pilot project. Nature $\mathbf{4 4 7}$ $799-816$
Bouche N, Lauressergues D, Gasciolli V \& Vaucheret H 2006 An antagonistic function for Arabidopsis DCL2 in development and a new function for DCL4 in generating viral siRNAs. EMBO Journal 25 $3347-3356$.

Brosnan CA, Mitter N, Christie M, Smith NA, Waterhouse PM \& Carroll BJ 2007 Nuclear gene silencing directs reception of longdistance mRNA silencing in Arabidopsis. PNAS 104 14741-14746.

Chandler VL 2007 Paramutation: from maize to mice. Cell 128 641-645.

Cuzin F 2007 Induction by microRNAs of hereditary epigenetic modifications (paramutation) in the mouse. Proceedings of the 5 th Colmar Symposium: The New RNA Frontiers, Colmar, France.

Deleris A, Gallego-Bartolome J, Bao J, Kasschau KD, Carrington JC \& Voinnet O 2006 Hierarchical action and inhibition of plant dicerlike proteins in antiviral defense. Science 313 68-71.

Duxbury MS, Ashley SW \& Whang EE 2005 RNA interference: a mammalian SID-1 homologue enhances siRNA uptake and gene silencing efficacy in human cells. Biochemical and Biophysical Research Communications 331 459-463.

Eyman M, Cefaliello C, Ferrara E, De Stefano R, Lavina ZS, Crispino M, Squillace A, van Minnen J, Kaplan BB \& Giuditta A 2007 Local synthesis of axonal and presynaptic RNA in squid model systems. European Journal of Neuroscience 25 341-350.

Feinberg EH \& Hunter CP 2003 Transport of dsRNA into cells by the transmembrane protein SID-1. Science 301 1545-1547.

Fevrier B \& Raposo G 2004 Exosomes: endosomal-derived vesicles shipping extracellular messages. Current Opinion in Cell Biology 16 $415-421$.

Fevrier B, Vilette D, Laude H \& Raposo G 2005 Exosomes: a bubble ride for prions? Traffic 6 10-17.

Fire A, Xu S, Montgomery MK, Kostas SA, Driver SE \& Mello CC 1998 Potent and specific genetic interference by double-stranded RNA in Caenorhabditis elegans. Nature 391 806-811.

Fusaro AF, Matthew L, Smith NA, Curtin SJ, Dedic-Hagan J, Ellacott GA, Watson JM, Wang MB, Brosnan C, Carroll BJ et al. 2006 RNA interference-inducing hairpin RNAs in plants act through the viral defence pathway. EMBO Reports 7 1168-1175.

Gan L, Anton KE, Masterson BA, Vincent VA, Ye S \& Gonzalez-Zulueta M 2002 Specific interference with gene expression and gene function mediated by long dsRNA in neural cells. Journal of Neuroscience Methods 121 151-157.

Garcia-Perez RD, Houdt HV \& Depicker A 2004 Spreading of posttranscriptional gene silencing along the target gene promotes systemic silencing. Plant Journal 38 594-602.

Han J, Kim D \& Morris KV 2007 Promoter-associated RNA is required for RNA-directed transcriptional gene silencing in human cells. PNAS 104 12422-12427.

Hatada I, Morita S, Obata Y, Sotomaru Y, Shimoda M \& Kono T 2001 Identification of a new imprinted gene, Rian, on mouse chromosome 12 by fluorescent differential display screening. Journal of Biochemistry 130 187-190.

Himber C, Dunoyer P, Moissiard G, Ritzenthaler C \& Voinnet O 2003 Transitivity-dependent and -independent cell-to-cell movement of RNA silencing. EMBO Journal 22 4523-4533.

Ishii KJ \& Akira S 2005 TLR ignores methylated RNA? Immunity 23 111-113.

Jose AM \& Hunter CP 2007 Transport of sequence-specific RNA interference information between cells. Annual Review of Genetics 41 305-330.

Joyce GF 2002 The antiquity of RNA-based evolution. Nature $\mathbf{4 1 8}$ 214-221.

Kapranov P, Willingham AT \& Gingeras TR 2007a Genome-wide transcription and the implications for genomic organization. Nature Reviews Genetics 8 413-423.

Kapranov P, Cheng J, Dike S, Nix DA, Duttagupta R, Willingham AT, Stadler PF, Hertel J, Hackermuller J, Hofacker IL et al. $2007 b$ RNA maps reveal new RNA classes and a possible function for pervasive transcription. Science 316 1484-1488. 
Kariko K, Buckstein M, Ni H \& Weissman D 2005 Suppression of RNA recognition by Toll-like receptors: the impact of nucleoside modification and the evolutionary origin of RNA. Immunity 23 165-175.

Karpala AJ, Doran TJ \& Bean AG 2005 Immune responses to dsRNA: implications for gene silencing technologies. Immunology and Cell Biology 83 211-216.

Kim M, Canio W, Kessler S \& Sinha N 2001 Developmental changes due to long-distance movement of a homeobox fusion transcript in tomato. Science 293 287-289.

Kishore S \& Stamm S 2006 The snoRNA HBII-52 regulates alternative splicing of the serotonin receptor 2C. Science 311 230-232.

Kiss T 2002 Small nucleolar RNAs: an abundant group of noncoding RNAs with diverse cellular functions. Cell 109 145-148.

Kole R \& Sazani P 2001 Antisense effects in the cell nucleus: modification of splicing. Current Opinion in Molecular Therapeutics 3 229-234.

van der Krol AR, Mur LA, Beld M, Mol JN \& Stuitje AR 1990 Flavonoid genes in petunia: addition of a limited number of gene copies may lead to a suppression of gene expression. Plant Cell 2 291-299.

St Laurent G, III. \& Wahlestedt C 2007 Noncoding RNAs: couplers of analog and digital information in nervous system function? Trends in Neurosciences 30 612-621.

Lein ES, Hawrylycz MJ, Ao N, Ayres M, Bensinger A, Bernard A, Boe AF, Boguski MS, Brockway KS, Byrnes EJ et al. 2007 Genome-wide atlas of gene expression in the adult mouse brain. Nature 445 168-176.

Li H, Coghlan A, Ruan J, Coin LJ, Heriche JK, Osmotherly L, Li R, Liu T, Zhang Z, Bolund L et al. 2006 TreeFam: a curated database of phylogenetic trees of animal gene families. Nucleic Acids Research 34 D572-D580.

Lo YM 2005 Recent advances in fetal nucleic acids in maternal plasma. Journal of Histochemistry and Cytochemistry 53 293-296.

Martianov I, Ramadass A, Serra Barros A, Chow N \& Akoulitchev A 2007 Repression of the human dihydrofolate reductase gene by a non-coding interfering transcript. Nature 445 666-670.

Martinho RG, Kunwar PS, Casanova J \& Lehmann R 2004 A noncoding RNA is required for the repression of RNApolII-dependent transcription in primordial germ cells. Current Biology 14 159-165.

Mattick JS 1994 Introns: evolution and function. Current Opinion in Genetics and Development 4 823-831.

Mattick JS 2003 Challenging the dogma: the hidden layer of nonprotein-coding RNAs in complex organisms. BioEssays 25 930-939.

Mattick JS 2004 RNA regulation: a new genetics? Nature Reviews. Genetics 5 316-323.

Mattick JS 2007 A new paradigm for developmental biology. Journal of Experimental Biology 210 1526-1547.

Mattick JS \& Gagen MJ 2001 The evolution of controlled multitasked gene networks: the role of introns and other noncoding RNAs in the development of complex organisms. Molecular Biology and Evolution 18 1611-1630.

Mattick JS \& Makunin IV 2006 Non-coding RNA. Human Molecular Genetics 15 Spec No 1 R17-R29.

Mehler MF \& Mattick JS 2007 Noncoding RNAs and RNA editing in brain development, functional diversification, and neurological disease. Physiological Reviews 87 799-823.

Mercer TR, Dinger ME, Susan SM, Mehler MF \& Mattick JS 2008 Specific expression of long noncoding RNAs in the adult mouse brain. PNAS 105 716-721.

Mineno J, Okamoto S, Ando T, Sato M, Chono H, Izu H, Takayama M, Asada K, Mirochnitchenko O, Inouye M et al. 2006 The expression profile of microRNAs in mouse embryos. Nucleic Acids Research 34 $1765-1771$

Napoli C, Lemieux C \& Jorgensen R 1990 Introduction of a Chimeric Chalcone Synthase gene into petunia results in reversible co-suppression of homologous genes in trans. Plant Cell 2 279-289.

Ng EK, Tsui NB, Lam NY, Chiu RW, Yu SC, Wong SC, Lo ES, Rainer TH, Johnson PJ \& Lo YM 2002 Presence of filterable and nonfilterable mRNA in the plasma of cancer patients and healthy individuals. Clinical Chemistry 48 1212-1217.
Ohno M, Fukagawa T, Lee JS \& Ikemura T 2002 Triplex-forming DNAs in the human interphase nucleus visualized in situ by polypurine/polypyrimidine DNA probes and antitriplex antibodies. Chromosoma 111 201-213.

Okamoto I, Arnaud D, Le Baccon P, Otte AP, Disteche CM, Avner P \& Heard E 2005 Evidence for de novo imprinted X-chromosome inactivation independent of meiotic inactivation in mice. Nature 438 369-373.

Orgel LE 2004 Prebiotic chemistry and the origin of the RNA world. Critical Reviews in Biochemistry and Molecular Biology 39 99-123.

Palauqui JC, Elmayan T, Pollien JM \& Vaucheret H 1997 Systemic acquired silencing: transgene-specific post-transcriptional silencing is transmitted by grafting from silenced stocks to non-silenced scions. EMBO Journal 16 4738-4745.

Pheasant M \& Mattick JS 2007 Raising the estimate of functional human sequences. Genome Research 17 1245-1253.

Prasanth KV \& Spector DL 2007 Eukaryotic regulatory RNAs: an answer to the 'genome complexity' conundrum. Genes and Development 21 11-42.

Rassoulzadegan M, Grandjean V, Gounon P, Vincent S, Gillot I \& Cuzin F 2006 RNA-mediated non-mendelian inheritance of an epigenetic change in the mouse. Nature 441 469-474.

Ratajczak J, Wysoczynski M, Hayek F, Janowska-Wieczorek A \& Ratajczak MZ 2006a Membrane-derived microvesicles: important and underappreciated mediators of cell-to-cell communication. Leukemia 20 1487-1495.

Ratajczak J, Miekus K, Kucia M, Zhang J, Reca R, Dvorak P \& Ratajczak MZ 2006 $b$ Embryonic stem cell-derived microvesicles reprogram hematopoietic progenitors: evidence for horizontal transfer of mRNA and protein delivery. Leukemia 20 847-856.

Ravasi T, Suzuki H, Pang KC, Katayama S, Furuno M, Okunishi R, Fukuda S, Ru K, Frith MC, Gongora MM et al. 2006 Experimental validation of the regulated expression of large numbers of noncoding RNAs from the mouse genome. Genome Research 16 11-19.

Reynolds A, Anderson EM, Vermeulen A, Fedorov Y, Robinson K, Leake D, Karpilow J, Marshall WS \& Khvorova A 2006 Induction of the interferon response by siRNA is cell type- and duplex lengthdependent. RNA 12 988-993.

Rinn JL, Kertesz M, Wang JK, Squazzo SL, Xu X, Brugmann SA, Goodnough LH, Helms JA, Farnham PJ, Segal E et al. 2007 Functional demarcation of active and silent chromatin domains in human HOX loci by noncoding RNAs. Cell 129 1311-1323.

Russell L 1977 Movement of spermatocytes from the basal to the adluminal compartment of the rat testis. American Journal of Anatomy 148 313-328.

Rustom A, Saffrich R, Markovic I, Walther P \& Gerdes HH 2004 Nanotubular highways for intercellular organelle transport. Science 303 1007-1010.

Scott WG 2007 Ribozymes. Current Opinion in Structural Biology 17 280-286.

Sioud M 2006 Innate sensing of self and non-self RNAs by Toll-like receptors. Trends in Molecular Medicine 12 167-176.

Sleutels F, Zwart R \& Barlow DP 2002 The non-coding Air RNA is required for silencing autosomal imprinted genes. Nature $\mathbf{4 1 5}$ $810-813$.

Smith HA, Swaney SL, Parks TD, Wernsman EA \& Dougherty WG 1994 Transgenic plant virus resistance mediated by untranslatable sense RNAs: expression, regulation, and fate of nonessential RNAs. Plant Cell 6 1441-1453.

Sontheimer EJ 2005 Assembly and function of RNA silencing complexes. Nature Reviews Molecular Cell Biology 6 127-138.

Stein P, Zeng F, Pan H \& Schultz RM 2005 Absence of non-specific effects of RNA interference triggered by long double-stranded RNA in mouse oocytes. Developmental Biology 286 464-471.

Steinhauer J \& Kalderon D 2006 Microtubule polarity and axis formation in the Drosophila oocyte. Developmental Dynamics 235 $1455-1468$. 
Su AI, Wiltshire T, Batalov S, Lapp H, Ching KA, Block D, Zhang J, Soden R, Hayakawa M, Kreiman G et al. 2004 A gene atlas of the mouse and human protein-encoding transcriptomes. PNAS 101 6062-6067.

Tavernarakis N, Wang SL, Dorovkov M, Ryazanov A \& Driscoll M 2000 Heritable and inducible genetic interference by double-stranded RNA encoded by transgenes. Nature Genetics 24 180-183.

Thery C, Zitvogel L \& Amigorena S 2002 Exosomes: composition, biogenesis and function. Nature Reviews. Immunology 2 569-579.

Tijsterman M, May RC, Simmer F, Okihara KL \& Plasterk RH 2004 Genes required for systemic RNA interference in Caenorhabditis elegans. Current Biology 14 111-116.

Tsang JC \& Lo YM 2007 Circulating nucleic acids in plasma/serum. Pathology 39 197-207.

Tsui NB, Ng EK \& Lo YM 2002 Stability of endogenous and added RNA in blood specimens, serum, and plasma. Clinical Chemistry 48 $1647-1653$.

Tsui NB, Ng EK \& Lo YM 2006 Molecular analysis of circulating RNA in plasma. Methods in Molecular Biology 336 123-134.

Valadi H, Ekstrom K, Bossios A, Sjostrand M, Lee JJ \& Lotvall JO 2007 Exosome-mediated transfer of mRNAs and microRNAs is a novel mechanism of genetic exchange between cells. Nature Cell Biology 9 654-659.

Valiunas V, Polosina YY, Miller H, Potapova IA, Valiuniene L, Doronin S, Mathias RT, Robinson RB, Rosen MR, Cohen IS et al. 2005 Connexinspecific cell-to-cell transfer of short interfering RNA by gap junctions. Journal of Physiology $\mathbf{5 6 8}$ 459-468.

Vastenhouw NL, Brunschwig K, Okihara KL, Muller F, Tijsterman M \& Plasterk RH 2006 Gene expression: long-term gene silencing by RNAi. Nature 442882.

Vaucheret H \& Fagard M 2001 Transcriptional gene silencing in plants: targets, inducers and regulators. Trends in Genetics 17 29-35.

Ventela S, Toppari J \& Parvinen M 2003 Intercellular organelle traffic through cytoplasmic bridges in early spermatids of the rat: mechanisms of haploid gene product sharing. Molecular Biology of the Cell 14 2768-2780.

Voinnet O \& Baulcombe DC 1997 Systemic signalling in gene silencing. Nature 389553.
Wienholds E, Kloosterman WP, Miska E, Alvarez-Saavedra E, Berezikov E, de Bruijn E, Horvitz HR, Kauppinen S \& Plasterk RH 2005 MicroRNA expression in zebrafish embryonic development. Science 309 310-311.

Wiley RD \& Gummuluru S 2006 Immature dendritic cell-derived exosomes can mediate HIV-1 trans infection. PNAS 103 738-743.

Willingham AT, Orth AP, Batalov S, Peters EC, Wen BG, Aza-Blanc P, Hogenesch JB \& Schultz PG 2005 A strategy for probing the function of noncoding RNAs finds a repressor of NFAT. Science 309 $1570-1573$

Winkler WC \& Breaker RR 2005 Regulation of bacterial gene expression by riboswitches. Annual Review of Microbiology 59 487-517.

Winston WM, Molodowitch C \& Hunter CP 2002 Systemic RNAi in C. elegans requires the putative transmembrane protein SID-1. Science 295 2456-2459.

Winston WM, Sutherlin M, Wright AJ, Feinberg EH \& Hunter CP 2007 Caenorhabditis elegans SID-2 is required for environmental RNA interference. PNAS 104 10565-10570.

Wolfrum C, Shi S, Jayaprakash KN, Jayaraman M, Wang G, Pandey RK, Rajeev KG, Nakayama T, Charrise K, Ndungo EM et al. 2007 Mechanisms and optimization of in vivo delivery of lipophilic siRNAs. Nature Biotechnology 25 1149-1157.

Wolvetang EJ, Pera MF \& Zuckerman KS 2007 Gap junction mediated transport of shRNA between human embryonic stem cells. Biochemical and Biophysical Research Communications 363 610-615.

Yang S, Tutton S, Pierce E \& Yoon K 2001 Specific double-stranded RNA interference in undifferentiated mouse embryonic stem cells. Molecular and Cellular Biology 21 7807-7816.

Zhao Y, Samal E \& Srivastava D 2005 Serum response factor regulates a muscle-specific microRNA that targets Hand2 during cardiogenesis. Nature 436 214-220.

Received in final form 13 January 2008

Accepted 16 January 2008

Made available online as an Accepted Preprint

16 January 2008 